\title{
Polymorphisms on PAI-1 and ACE genes in association with fibrinolytic bleeding after on-pump cardiac surgery
}

Agnese Ozolina ${ }^{1,2+}{ }^{+}$, Eva Strike ${ }^{1,2}$, Liene Nikitina-Zake ${ }^{3 \dagger}$, Inta Jaunalksne ${ }^{4 \dagger}$, Angelika Krumina ${ }^{5}$, Romans Lacis ${ }^{1,2}$, Lars J. Bjertnaes ${ }^{6^{*}}$ and Indulis Vanags ${ }^{2}$

\begin{abstract}
Background: Carriers of plasminogen activator inhibitor -1 (PAI-1) - 675 genotype 5G/5G may be associated with lower preoperative PAl-1 plasma levels and higher blood loss after heart surgery using cardiopulmonary bypass (CPB). We speculate if polymorphisms of PAl-1 -844 A/G and angiotensin converting enzyme (ACE) intron 16 I/D also might promote fibrinolysis and increase postoperative bleeding.

Methods: We assessed PAI-1 -844 A/G, and ACE intron 16 I/D polymorphisms by polymerase chain reaction technique and direct sequencing of genomic DNA from 83 open heart surgery patients that we have presented earlier. As primary outcome, accumulated chest tube drainage (CTD) at 4 and $24 \mathrm{~h}$ were analyzed for association with genetic polymorphisms. As secondary outcome, differences in plasma levels of PAI-1, t-PA/PAl-1 complex and D-dimer were determined for each polymorphism. SPSS ${ }^{\circledR}$ was used for statistical evaluation.

Results: The lowest preoperative PAI-1 plasma levels were associated with PAI-1 -844 genotype G/G, and higher CTD, as compared with genotype A/A at 4 and $24 \mathrm{~h}$ after surgery. Correspondingly, $4 \mathrm{~h}$ after the surgery CTD was higher in carriers of ACE intron 16 genotype I/I, as compared with genotype D/D. PAI-1 plasma levels and t-PA/PAI-1 complex reached nadir in carriers of ACE intron 16 genotype I/I, in whom we also noticed the highest D-dimer levels immediately after surgery. Notably, carriers of PAl-1 -844 genotype $\mathrm{G} / \mathrm{G}$ displayed higher D-dimer levels at $24 \mathrm{~h}$ after surgery as compared with those of genotype $\mathrm{A} / \mathrm{G}$.

Conclusions: Increased postoperative blood loss secondary to enhanced fibrinolysis was associated with carriers of PAI-1 -844 G/G and ACE Intron $16 \mathrm{I} / \mathrm{l}$, suggesting that these genotypes might predict increased postoperative blood loss after cardiac surgery using CPB.
\end{abstract}

\section{Background}

Heart surgery by means of cardiopulmonary bypass (CPB) can impede hemostasis, thereby increasing postoperative bleeding and the need for blood transfusions $[1,2]$. Recently, investigators reported that more than $40 \%$ of the cases of excessive bleedings after this kind of surgery are due to coagulopathy [3]. The balance between bleeding, normal hemostasis and thrombosis is significantly influenced by platelet aggregation, rate of

\footnotetext{
* Correspondence: lars.bjertnaes@uit.no

${ }^{\dagger}$ Equal contributors

${ }^{6}$ Anesthesia and Critical Care Research Group, Department of Clinical Medicine, Faculty of Health Sciences, University of Tromsø, 9037 Troms $\varnothing$, Norway

Full list of author information is available at the end of the article
}

thrombin formation and activation of the fibrinolytic system. Recent evidence suggests that genetic variability might influence the activation of each of these pathways $[4,5]$.

During CPB, fibrinolytic activity increases 10 - to 100fold because of augmented generation of plasmin, triggered by a rise in tissue plasminogen activator ( $t-P A)$, ultimately resulting in enhanced plasma concentration of fibrin degradation products [6, 7]. Plasminogen activator inhibitor type-1 (PAI-1), the main inhibitor of fibrinolysis, increases a 15 -fold only $2 \mathrm{~h}(\mathrm{~h})$ after cardiac surgery, as a part of the "fibrinolytic shut down" $[1,8]$. In a previous study of patients, who underwent cardiac surgery on $\mathrm{CPB}$, we found that lower plasma concentrations of PAI-1 preoperatively were associated with more 
bleeding, lower levels of t-PA/PAI-1 complex, and higher D-dimer concentrations postoperatively [9].

The PAI-1 gene contains more polymorphisms. The promoter regions 675 4Guanine/5Guanine (4G/5G) and -844 Adenosine/Guanine (A/G) polymorphisms, both affecting the fibrinolytic balance, are two of the most common. Reassessing blood from the latter study [9], we recently confirmed the findings of other investigators that in addition to decreased plasma levels of PAI-1, excessive bleeding after CPB was associated with PAI-1 -675 5G/5G polymorphism [5, 10-14].

Although primarily an endocrine long-term regulator of blood pressure and extracellular volume, the reninangiotensin-aldosterone system (RAAS) also plays a pivotal role in the regulation of fibrinolysis. Angiotensin converting enzyme (ACE) influences PAI-1 plasma levels by converting angiotensin I to angiotensin II $[15,16]$. Recent studies suggest that increased fibrinolysis is mainly related to inhibition of angiotensin II, which acts by reducing the plasma level of PAI-1 rather than increasing that of t-PA [17]. However, plasma concentrations of both PAI-1 and t-PA are characterized by wide inter-individual variations, most likely because of differences in ACE plasma concentrations $[18,19]$.

Lately, very long half-life PAI-1 seems to represent a promising treatment option for genetically predisposed individuals with low levels of PAI-1 [20]. PAI-1 gene $-844 \mathrm{~A} / \mathrm{G}$ polymorphism has been associated with both coronary heart disease [21, 22], and venous thrombosis resulting from decreased fibrinolysis [22, 23]. However, to our knowledge, no previous investigation has documented association between PAI-1 -844 A/G polymorphism and increased blood loss due to increased fibrinolysis after cardiac surgery employing CPB.

Intron 16 Insertion/Deletion (I/D) polymorphism of the $A C E$ gene influences concentration of circulating ACE, thereby affecting endogenously generated inhibitor of fibrinolysis. The insertion allele is believed to steer approximately one half of the plasma levels of ACE and PAI-1, and might potentially increase fibrinolytic activity [24]. Several studies have revealed that $A C E$ intron $16 \mathrm{I} / \mathrm{D}$ polymorphism is accompanied by a wide range of cardiovascular diseases. Genotype D/D is associated both with increased plasma concentration and higher activity of PAI-1 [25-28]. However, the ACE Intron 16 I/D polymorphism has been sparsely studied, as a potential cause of postoperative bleeding, and with controversial results $[25,29,30]$. Consequently, by examining the same patient cohort as referred to above [14], our primary end-point was to address the associations between PAI-1 -844 A/G and ACE Intron $16 \mathrm{I} / \mathrm{D}$ polymorphisms and fibrinolytic bleeding after cardiac surgery using $\mathrm{CPB}$.

\section{Methods}

Methods has been presented previously in this journal [9] and will only be shortly described. A more extensive version is available, see Additional file 1. The protocol and the informed consent form, including the request to donate genetic material, were approved by the Ethics Committee of Pauls Stradins Clinical University Hospital, Riga, Latvia. All patients provided written informed content.

In short, 90 consecutive adult patients were admitted to the hospital to undergo cardiac surgery with $\mathrm{CPB}$, whereof 7 were excluded at the reoperation because of surgical bleeding. Postoperative bleeding volumes were recorded as chest tube drainage (CTD) in $\mathrm{mL}$ at 4 and $24 \mathrm{~h}$ after the surgery [9]. Inclusion and exclusion criteria, as well as perioperative management, postoperative bleeding and demographic and laboratory data were the same as published before [9] and genomic DNA was extracted as reported by Ozolina et al. [14]. Here, we only describe the methods used for analysis of PAI-1 -844 A/G and ACE Intron 16 I/D polymorphisms.

\section{PAI-1 -844 A/G and ACE Intron 16 I/D}

Genomic DNA from whole blood of every patient was diluted in $1 \mathrm{ml}$ of water and stored on minus $70{ }^{\circ} \mathrm{C}$ until analyzed. The region harboring the PAI-1 -844 A/G gene polymorphism was amplified using polymerase chain reaction (PCR). The primers had the following sequences: 5' -ATCCCTTTTCCCCTTGTGTC-3' and 5' -AACCTC CATCAAAACGTGGA-3'. The PCR products were then purified using Sap/Exo I (Thermo Scientific ${ }^{\circ}$ Fermentas, Lithuania) and sequenced on an ABI Prizm 3130xl genetic analyzer (Applied Biosystems ${ }^{\circ}$, Life Technologies, USA).

For determination of $A C E$ Intron16 I/D polymorphism, we used the method published by Tomita et al. [31]. Insertion and deletion alleles were identified by using PCR amplification of the respective fragments from Intron 16. Fragment size was determined by agarose gel electrophoresis. The deletion allele was visualized at 191 base pairs (bp), and an insertion allele at $478 \mathrm{bp}$. For patients with /D genotype additional PCR was performed to verify the result of amplification.

\section{Statistical analysis}

Data were analyzed with SPSS (SPSS ${ }^{\circ}$ version 20.0, Chicago, IL). Continuous variables were presented as mean \pm standard deviation (SD) and categorical variables as percentages (\%). The data of the study groups were checked by an appropriate analytic test according to the data distribution. Comparisons between genotype groups were performed with KruskalWallis $\mathrm{H}$ test for non-parametric variables, and with ANOVA for parametric variables. Chi-square test was 
used to analyze categorical data. Statistical significance was defined as $P<0.05$.

\section{Results}

\section{Clinical course}

Out of totally, 90 consecutive patients scheduled for first time cardiac surgery, 83 patients, 42 men and 41 women, who met inclusion criteria were subjected to further analysis (Table 1). Patients were classified with their PAI-1-844 A/G and ACE Intron $16 \mathrm{I} / \mathrm{D}$ characteristics and subdivided into 3 groups, according to the genotype of each polymorphism. The genotype results of PAI-1 -844 A/G and ACE Intron $16 \mathrm{I} / \mathrm{D}$ polymorphisms were all in Hardy-Weinberg equilibrium. We noticed no significant differences between $\mathrm{CPB}$ priming - and cardioplegia volumes in relation to the different genotypes. We found no associations between PAI-1 -844 A/G genotype and demographic characteristics, preoperative parameters and surgical variables (Table 1). ACE of genotypes $\mathrm{I} / \mathrm{D}$ and $\mathrm{D} / \mathrm{D}$ were significantly more represented among males $(P<0.05)$ and in patients undergoing mixed type of surgery $(P<0.05)$.

\section{Relationships between PAI-1 -844 A/G and ACE Intron 16 I/D polymorphisms and postoperative bleeding}

Table 2 shows preoperative PAI-1, postoperative t-PA/ PAI-1 complex and D-dimer plasma levels in relation to PAI-1-844 A/G and ACE Intron $16 \mathrm{I} / \mathrm{D}$ polymorphisms. Mean PAI-1 plasma concentration was lower in carriers of genotype G/G, as compared to A/ A $(P=0.004)$, but no significant difference existed between genotypes $\mathrm{A} / \mathrm{A}$ and $\mathrm{A} / \mathrm{G}$. Mean plasma concentrations of t-PA/PAI-1 complex determined $24 \mathrm{~h}$ postoperatively displayed no significant differences between the PAI-1-844 genotype groups. In contrast, D-dimer levels differed significantly between carriers of genotypes $\mathrm{G} / \mathrm{G}$ and $\mathrm{A} / \mathrm{G} \quad(P=0.04)$ at $24 \mathrm{~h}$ (Table 2). As depicted in Fig. 1, carriers of PAI-1-844 genotype G/G displayed the greatest blood loss at 4

Table 1 Perioperative characteristics of patients scheduled for on-pump cardiac surgery

\begin{tabular}{|c|c|c|c|c|c|c|}
\hline \multirow{2}{*}{$\begin{array}{l}\text { Characteristics } \\
\text { Genotype }\end{array}$} & \multicolumn{3}{|c|}{ PAl-1 -844 A/G } & \multicolumn{3}{|c|}{ ACE Intron 16 I/D } \\
\hline & $\mathrm{G} / \mathrm{G}$ & $A / G$ & $\mathrm{~A} / \mathrm{A}$ & $|/|$ & I/D & $\mathrm{D} / \mathrm{D}$ \\
\hline Number of patients, $\mathrm{n}$ & 22 & 387 & 23 & 22 & 42 & 19 \\
\hline \multicolumn{7}{|l|}{ Demographic data } \\
\hline Age, yr & $61 \pm 11$ & $68 \pm 10$ & $67 \pm 11$ & $68 \pm 10$ & $66 \pm 10$ & $63 \pm 14$ \\
\hline Male sex, n (\%) & $15(68)$ & $16(42)$ & $11(48)$ & $9(41)^{*}$ & $23(55)^{* * *}$ & $10(53)^{* *}$ \\
\hline $\mathrm{BMI}, \mathrm{kg} / \mathrm{m}^{2}$ & $28 \pm 5$ & $28 \pm 8$ & $27 \pm 5$ & $27 \pm 5$ & $28 \pm 5$ & $27 \pm 4$ \\
\hline$E F,(\%)$ & $57 \pm 8$ & $55 \pm 8$ & $56 \pm 7$ & $58 \pm 6$ & $55 \pm 9$ & $55 \pm 7$ \\
\hline \multicolumn{7}{|l|}{ Type of surgery, n (\%) } \\
\hline CABG, n (\%) & $11(50)$ & $15(40)$ & $8(35)$ & $8(36)$ & $18(43)$ & $8(42)$ \\
\hline Valve, n (\%) & $8(36)$ & $13(34)$ & $10(43)$ & $9(41)$ & $13(31)$ & $9(47)$ \\
\hline Mixed, n (\%) & $3(14)$ & $10(26)$ & $5(22)$ & $5(23)^{*}$ & $11(26)^{* * *}$ & $2(11)^{* *}$ \\
\hline \multicolumn{7}{|l|}{ Surgical variables } \\
\hline CPB duration (min) & $110 \pm 42$ & $106 \pm 42$ & $99 \pm 37$ & $101 \pm 47$ & $105 \pm 39$ & $109 \pm 37$ \\
\hline Aorta oclusion time (min) & $69 \pm 30$ & $65 \pm 25$ & $63 \pm 11$ & $64 \pm 27$ & $65 \pm 27$ & $69 \pm 29$ \\
\hline Reperfusion time (min) & $33 \pm 12$ & $33 \pm 15$ & $33 \pm 16$ & $29 \pm 13$ & $36 \pm 17$ & $33 \pm 9$ \\
\hline $\mathrm{CPB}$ priming volume, $\mathrm{ml}$ & $1864 \pm 543$ & $1509 \pm 516$ & $1329 \pm 440$ & $1379 \pm 462$ & $1548 \pm 556$ & $1544 \pm 482$ \\
\hline Cardioplegia, ml & $1872 \pm 587$ & $1673 \pm 516$ & $1886 \pm 674$ & $1647 \pm 523$ & $1833 \pm 655$ & $1836 \pm 478$ \\
\hline \multicolumn{7}{|l|}{ Preoperative parameters } \\
\hline Hemoglobin, g/dL & $136 \pm 15$ & $139 \pm 13$ & $131 \pm 18$ & $132 \pm 17$ & $137 \pm 16$ & $138 \pm 12$ \\
\hline Platelet count, $\times 10^{9} / \mathrm{L}$ & $221 \pm 67$ & $215 \pm 50$ & $215 \pm 63$ & $211 \pm 45$ & $218 \pm 65$ & $220 \pm 58$ \\
\hline Prothrombin time, $\%$ & $84 \pm 15$ & $90 \pm 14$ & $92 \pm 12$ & $94 \pm 15$ & $89 \pm 13$ & $85 \pm 14$ \\
\hline Fibrinogen, $\mathrm{g} / \mathrm{L}$ & $4.4 \pm 1.3$ & $4.6 \pm 1.2$ & $4.7 \pm 1.5$ & $4.5 \pm 1.2$ & $4.6 \pm 1.2$ & $4.7 \pm 3.7$ \\
\hline
\end{tabular}

Data presented as the mean \pm standard error of the mean

PAI-1 Plasminogen activator inhibitor type-1, A Adenosine, G Guanine, ACE Angiotensin converting enzyme, I Insertion, $D$ Deletion, $n$ Number of patients, BMI Body mass index, EF Ejection fraction, $C A B G$ Coronary artery bypass grafting, CPB Cardiopulmonary bypass. ${ }^{*} P<0.05$ between $A C E$ Intron 16 I/I and I/D genotypes;

${ }^{* *} P<0.05$ between ACE Intron $16 \mathrm{D} / \mathrm{D}$ andl/D genotypes 
Table 2 PAI-1 -844 A/G and ACE Intron 16 I/D gene polymorphisms related to markers of fibrinolysis. Plasma concentrations of PAI-1 preoperatively - and of t-PA/PAl-1 complex and D-dimer postoperatively after on-pump cardiac surgery

\begin{tabular}{|c|c|c|c|c|c|c|}
\hline Genetic polymorphism & $\mathrm{n}$ & $\begin{array}{l}\text { PAl-1, ng/mL, } \\
\text { preoperatively }\end{array}$ & $\begin{array}{l}\mathrm{t}-\mathrm{PA} / \mathrm{PAl}-1, \mathrm{ng} / \mathrm{mL}, \\
24 \mathrm{~h} \text { postoperatively }\end{array}$ & D-dimer, ng/mL $0 \mathrm{~h}$ & D-dimer, ng/mL $6 \mathrm{~h}$ & D-dimer, ng/mL 24 h \\
\hline \multicolumn{7}{|l|}{ PAI-1 -844 A/G } \\
\hline $\mathrm{A} / \mathrm{A}$ & 23 & $28 \pm 12^{*}$ & $3.8 \pm 1.8$ & $251 \pm 170$ & $289 \pm 210$ & $234 \pm 187$ \\
\hline$A / G$ & 38 & $24 \pm 13$ & $3.6 \pm 2.1$ & $312 \pm 213$ & $312 \pm 200$ & $184 \pm 129^{*}$ \\
\hline $\mathrm{G} / \mathrm{G}$ & 22 & $18 \pm 12^{*}$ & $3.4 \pm 2.4$ & $287 \pm 255$ & $255 \pm 203$ & $267 \pm 168^{*}$ \\
\hline$P$ value & & 0.004 & NS & NS & NS & 0.04 \\
\hline \multicolumn{7}{|l|}{ ACE intron $16 \mathrm{I} / \mathrm{D}$} \\
\hline $\mathrm{D} / \mathrm{D}$ & 19 & $27 \pm 13^{*}$ & $3.6 \pm 2$ & $234 \pm 161^{*}$ & $244 \pm 182$ & $208 \pm 173$ \\
\hline I/D & 42 & $24 \pm 13$ & $4 \pm 2.3^{*}$ & $294 \pm 238$ & $291 \pm 204$ & $247 \pm 165$ \\
\hline |/| & 22 & $18 \pm 11^{*}$ & $2.8 \pm 1.7^{*}$ & $376 \pm 203^{*}$ & $331 \pm 218$ & $274 \pm 167$ \\
\hline$P$ value & & 0.02 & 0.02 & 0.03 & NS & NS \\
\hline
\end{tabular}

Data presented as the mean \pm standard error of the mean

PAl-1 Plasminogen activator inhibitor type-1, A Adenosine, $G$ Guanine, ACE Angiotensin converting enzyme, $I$ Insertion, $D$ Deletion, $n$ Number of patients, $t$-PA Tissue plasminogen activator, $O \mathrm{~h}$ Immediately after surgery, $6,24 \mathrm{~h} 6$ and $24 \mathrm{~h}$ postoperatively. ${ }^{*} P<0.05$ between genotypes

and $24 \mathrm{~h}$ postoperatively, as compared with carriers of genotype A/A $(P=0.0001, P=0.03$, respectively).

Carriers of $A C E$ Intron 16 genotype I/I presented with significantly lower preoperative plasma concentrations of PAI-1, as compared with carriers of genotype D/D $(P=0.02)$, but not as compared with carriers of genotype I/D (Table 2). Concerning t-PA/PAI-1 complex determined $24 \mathrm{~h}$ after the surgery (Table 2), we found higher plasma concentrations in carriers of genotypes

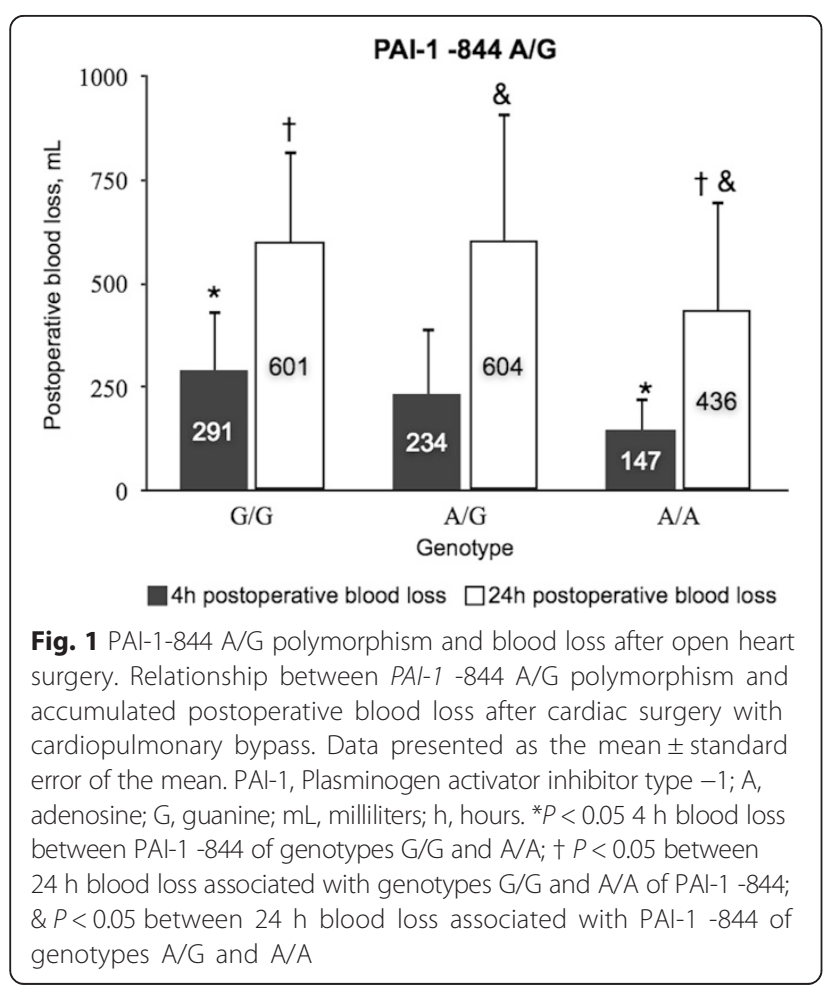

I/D as compared with I/I $(P=0.02)$. Postoperatively, patients with $A C E$ Intron 16 genotype I/I displayed higher plasma concentrations of D-dimer at all three time points. The difference reached significance immediately after the surgery (Table 2) in carriers of genotype $\mathrm{I} / \mathrm{I}$ in comparison with genotype $\mathrm{D} / \mathrm{D}(P=0.03)$. Correspondingly, as shown in Fig. 2, carriers of genotype $\mathrm{I} / \mathrm{I}$ also presented with significantly higher blood loss $4 \mathrm{~h}$ after surgery, in comparison with genotypes I/D $(P=0.02)$ and $\mathrm{D} / \mathrm{D}(P=0.04)$.

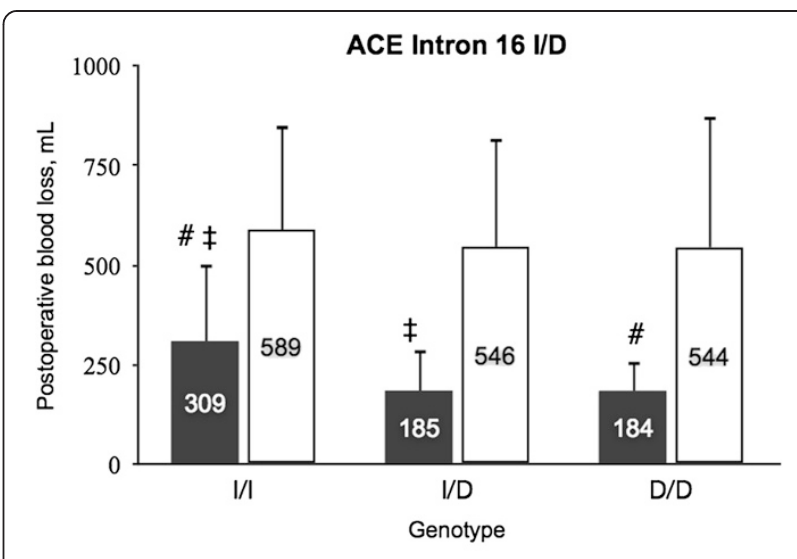

4h postoperative blood loss $\square 24 \mathrm{~h}$ postoperative blood loss

Fig. 2 ACE Intron 16 l/D polymorphism and blood loss after open heart surgery. Relationship between ACE Intron 16 I/D polymorphism and accumulated postoperative blood loss after cardiac surgery with cardiopulmonary bypass. Data presented as the mean \pm standard error of the mean. ACE, Angiotensin Converting Enzyme; l, insertion; $\mathrm{D}$, deletion; $\mathrm{mL}$, milliliters; $\mathrm{h}$, hours. \# $P<0.05$ between $4 \mathrm{~h}$ blood loss associated with ACE Intron 16 of genotypes $I / /$ and $D / D ; \neq P<0.05$ between $4 \mathrm{~h}$ blood loss associated with ACE Intron 16 of genotypes $\mathrm{I} / \mathrm{I}$ and $\mathrm{I} / \mathrm{D}$ 


\section{Discussion}

This study revealed that blood loss after cardiac surgery with extracorporeal circulation is larger in carriers of PAI-1 -844 genotype G/G and ACE intron 16 genotype $\mathrm{I} / \mathrm{I}$ as compared with their respective genotypes $\mathrm{A} / \mathrm{A}$ and $\mathrm{D} / \mathrm{D}$. We also noticed the lowest preoperative plasma concentrations of PAI-1 and the highest D-dimer levels $24 \mathrm{~h}$ after the surgery in carriers of PAI-1-844 genotype G/G. Correspondingly, in carriers of $A C E$ intron 16 genotype $\mathrm{I} / \mathrm{I}, \mathrm{D}$-dimer plasma concentration peaked transiently immediately after the surgery and t-PA/PAI-1 complex reached nadir at $24 \mathrm{~h}$ postoperatively.

PAI-1 and t-PA forming t-PA/PAI-1 complex, are supposed to be the main regulators of fibrinolysis in human. According to a recent study, patients with myocardial infarction presented with higher PAI-1 and lower t-PA plasma concentrations as compared with healthy controls [21]. Notably, regression analysis confirmed an independent association between myocardial infarction and genotype $-844 \mathrm{~A} / \mathrm{A}$ in concert with pronounced elevation of PAI-1 [22]. Consistent with the increased anti-fibrinolytic activity associated with myocardial infarction, our findings indicate that genotype A/A rather protects against fibrinolysis, as assessed by a lower accumulated blood loss $24 \mathrm{~h}$ postoperatively in carriers of that genotype.

\section{PAl-1-844 A/G polymorphisms}

We believe that increased fibrinolysis, as assessed by lower plasma concentrations of PAI-1 and t-PA/PAI-1 complex can explain the augmented blood loss in carriers of PAI-1-844 genotype G/G. As compared with heterozygotes and carriers of PAI-1 -844 A/A, those of genotype $G / G$ presented with significantly larger blood loss and the significantly highest $\mathrm{D}$-dimer plasma concentrations at $24 \mathrm{~h}$. The latter genotype also demonstrated a $36 \%$ reduction in preoperative PAI-1 plasma concentration, as compared with carriers of genotype $\mathrm{A} / \mathrm{A}$. This is consistent with observations made by previous investigators in healthy volunteers [32]. Studying PAI-1-844 A/G and PAI-1 -675 (4G/5G) polymorphisms, the latter workers showed that carriers of genotype G-5G had significantly lower plasma concentrations of PAI-1. They also noticed that the plasma level of PAI-1 depends more on body mass index than on PAI-1 promoter variations, a contention we could not confirm in the present study. In carriers of genotype G/G, we also were unable to demonstrate increased fibrinolysis at 0 and $6 \mathrm{~h}$ postoperatively, despite the fact that this genotype displayed the significantly highest plasma level of D-dimer $24 \mathrm{~h}$ after surgery. We interpret this result as a of lower inhibitory fibrinolytic potential, which is consistent with the "fibrinolytic shut down", that might occur in parallel with maximum D-dimer levels $24 \mathrm{~h}$ after the operation [33].

\section{ACE Intron $16 \mathrm{l} / \mathrm{D}$ polymorphisms}

Several investigators have focused on a potential association between $A C E$ Intron 16 I/D polymorphism and increased postoperative bleeding after cardiac surgery $[25,28-30,34]$. Prior to surgery, we observed $33 \%$ significantly higher preoperative plasma concentrations of PAI-1 in carriers of $A C E$ Intron 16 of genotype $\mathrm{D} / \mathrm{D}$, as compared with genotype I/I. The latter genotype also displayed significantly lower plasma levels of t-PA/PAI-1 complex and higher levels of D-dimer postoperatively, as compared with genotype I/D. The finding that those with the Dallele displayed the highest plasma levels of PAI-1 agrees with a report evaluating the association between plasma PAI-1 levels and ACE Intron $16 \mathrm{I} / \mathrm{D}$ polymorphism in healthy volunteers [18]. Despite we observed more blood loss $4 \mathrm{~h}$ after the surgery in carriers of genotype I/I, we found no significant differences between the three genotypes $24 \mathrm{~h}$ postoperatively. Most likely, the increased blood loss was caused by fibrinolysis. According to previous investigators, plasma concentration of PAI-1 does not rise earlier than $2-3 \mathrm{~h}$ after the surgery [1]. The fact that carriers of genotype I/I had the lowest postoperative levels of t-PA/PAI-1 complex (Table 2) strengthens the assumption of an increased fibrinolytic tendency in association with that particular genotype. Other investigators also have reported significant associations between $A C E 16 \mathrm{I} / \mathrm{D}$ polymorphism and postoperative blood loss 12 and $24 \mathrm{~h}$ after open heart surgery $[28,29]$. In one investigation, the $\mathrm{D}$ allele was associated with decreased bleeding consistent with our finding [28]. In contrast, other investigators found larger blood loss $24 \mathrm{~h}$ postoperatively in carriers of $A C E$ Intron 16 genotype $\mathrm{I} / \mathrm{I}$ [30].

In carriers of $A C E$ Intron 16 genotype $\mathrm{D} / \mathrm{D}$ undergoing non-cardiac surgery, researchers observed decreased bleeding tendency in association with higher plasma concentrations of ACE [28]. Investigators studying the influence of $A C E$ polymorphism on intra - and postoperative bleeding in patients undergoing total hip replacement showed that carriers of D/D and I/D genotypes had the highest total blood losses [25]. In contrast to our findings, these workers suggest that the D allele should be considered as a risk factor of increased bleeding. In their work, patients of genotype I/I displayed higher D-dimer concentrations, suggesting that more efficient activation of coagulation had taken place, consistent with the higher Ddimer levels observed immediately after surgery in the present study. However, the latter investigators did not determine the PAI-1 and t-PA/PAI-1 plasma concentrations that corresponded with the ACE $16 \mathrm{I} / \mathrm{D}$ polymorphism. Possibly, higher plasma levels of ACE, PAI-1 and t-PA/ PAI-1 complex, combined with angiotensin-II-induced increase in vasoconstrictor tone, could explain these findings. Thus, although no general agreement has been reached, we and other investigators support the idea that 
a greater bleeding tendency might occur in carriers of $A C E$ Intron 16 of genotype I/I [29, 30, 34].

\section{Limitations}

Firstly, we admit that the sample size was too low to reach significant difference with, at least $80 \%$ power, and $5 \%$ significance level for analysis of every genetic polymorphism. We compared t-PA/PAI-1 complex plasma concentrations of 22 and 23 patients of genotypes G/G and A/A, respectively, and found that sample sizes of at least 159 patients in each group would be required to reach significant differences between the genotypes (Table 2). We wondered whether simultaneous occurrence of PAI-1 -844 G/G and $A C E$ Intron $16 \mathrm{I} / \mathrm{I}$ would give rise to excessive blood loss, or that PAI-1 -844 A/A and $A C E$ Intron $16 \mathrm{D} / \mathrm{D}$ would result in less blood loss postoperatively, but sample sizes were too low for such analysis. We also admit as a weakness that we did not include a group of healthy volunteers.

We correlated two gene polymorphisms with the plasma concentrations of individual fibrinolytic factors, but do admit that other confounding factors, like hypothermia, hemodilution, heparin re-bound and platelet damage also might have affected postoperative blood loss after surgery. Some investigators argue that reduction of body temperature lowers endogenous production of PAI-1, thereby giving rise to enhanced fibrinolysis and increased bleeding [35], whereas others refute this idea [36]. We rewarmed the patients to normal body temperature $\left(36.6{ }^{\circ} \mathrm{C}\right)$ before transfer to the recovery rooms. Therefore, it is unlikely that hypothermia reduced the formation of t-PA/PAI-1 complex and increased postoperative bleeding in these patients.

Consumption of coagulation factors and hemodilution (Table 1) also might have contributed to increased blood loss postoperatively [37]. We do not deny, that t-PA/ PAI-1 plasma levels occasionally decreased $24 \mathrm{~h}$ after the surgery due to the combination of hemodilution and decreased anti-fibrinolytic plasma proteins [6]. However, at $24 \mathrm{~h}$ postoperatively, we assume that patients had regained normovolemia because a negative net fluid balance was created upon admission to ICU.

It is hard to distinguish clinically changes in fibrinolysis from coagulation disturbances. We admit as a limitation, that neither euglobulin clot lysis time nor thromboelastography/thromboelastometry (TEG/ROTEM) were performed, although some studies predicate a limited role of the latter tests for detecting fibrinolysis [38, 39]. According to recent studies, TEG/ROTEM can only detect severe fibrinolysis in $5 \%$ of cases as compared to $57 \%$ of the cases of moderate fibrinolysis diagnosed with fibrinolytic markers, such as antiplasmin-plasmin complex [39]. Lower thresholds have been suggested for detecing 30minute fibrinolysis (LY30) by TEG [38]. Despite the fact that our patients received tranexamic acid during $\mathrm{CPB}$, fibrinolytic markers were analyzed only preoperatively and at $24 \mathrm{~h}$ postoperatively. At the latter time point, we assume that $90 \%$ of the anti-fibrinolytic agents were excreted via the urine [40]. Nonetheless, after elimination of other possible causes of bleeding, we found a correlation between our commonly used markers of fibrinolysis and specific genotypes.

\section{Conclusions}

The present study demonstrates that increased postoperative blood loss in patients subjected to cardiac surgery with the use of $\mathrm{CPB}$ might be caused by increased fibrinolysis secondary to decreased plasma concentration of PAI-1 due to PAI-1 -844 G/G or ACE Intron $16 \mathrm{I} / \mathrm{I}$ polymorphisms. We suggest that screening for genetic polymorphisms might become part of future pre-operative routines in order to prevent risks for postoperative bleeding due to disorders in the coagulation - or the fibrinolytic systems.

\section{Additional file}

Additional file 1: Supplemental methods. (PDF $94 \mathrm{~kb}$ )

\section{Abbreviations}

ACE 16 intron I/D: Angiotensin converting enzyme insertion/deletion gene polymorphism at 16-intron (rs4646994); ACT: Activated coagulation time; BMl: Body mass index; CABG: Coronary artery bypass grafting;

CPB: Cardiopulmonary bypass; CTD: Chest tube drainage; EuroSCORE: European system for cardiac operative risk evaluation; Hb: Hemoglobin; ICU: Intensive care unit; kg: Kilograms; LMWH: Low molecular weight heparin; PAl-1: Plasminogen activator inhibitor type-1; PAl-1-675 (4G5G): Plasminogen activator inhibitor -1 gene 4 Guanine/5Guanine polymorphism at position 675 (rs1799768); PAl-1-844 A/G: Plasminogen activator inhibitor type-1 Adenosine/Guanine polymorphism at position 844 (rs2227631); PCR: Polymerase chain reaction; PLT: Platelets; RAAS: Renin angiotensin aldosteron system; SD: Standard deviation; s: Seconds; TEG/ROTEM: Thromboelastography/thromboelastometry; t-PA: Tissue plasminogen activator; t-PA/PAI-1: Complex of tissue plasminogen activator and plasminogen activator inhibitor type-1; $0 \mathrm{~h}$ : Time point immediately after surgery; $4 \mathrm{~h}$ : Time point $4 \mathrm{~h}$ after surgery; $6 \mathrm{~h}$ : Time point $6 \mathrm{~h}$ after surgery; $24 \mathrm{~h}$ : Time point $24 \mathrm{~h}$ after surgery.

\section{Competing interests}

The authors declare that they have no competing interests.

\section{Authors' contributions}

$\mathrm{AO}$ and ES conceived the study. ES was responsible for anesthesia and applied the same anesthetic procedure in all the patients. $A O, R L$ participated in the design and the administration of the study. $\mathrm{AO}$ informed the patients and obtained their written consent. IV, AK and AO collected the clinical and laboratory data for analysis. IJ carried out the fibrinolysis immunoassays and interpreted the results. LNZ extracted genomic DNA and identified the polymorphisms. AO and ES performed the statistical analysis and interpreted the data. AO, IV, ES and LB drafted the manuscript. All authors read and approved the final manuscript.

\section{Acknowledgements}

Dr. Agnese Ozolina presented preliminary results from this study at the Best Abstracts Competition 2013, arranged by The European Society of Anesthesiology in Barcelona, Spain, and was awarded the third price (https://www.esahq.org/congresses/past-esa-congresses/euroanaesthesia2013/best-abstract-prize-competition/). The study was supported by grant 2009/0147/ 1DP/1.1.2.1.2/09/IPIANIAA/009 from the European Social Fund and from University of Troms $\varnothing$ Publication Fund. 


\section{Author details}

${ }^{1}$ Department of Cardiac surgery, Pauls Stradins Clinical University Hospital, Pilsonu Street 13, Riga, Latvia. ${ }^{2}$ Riga Stradins University, Dzirciema Street 16, Riga, Latvia. ${ }^{3}$ Latvian Biomedical Research and Study Center, Ratsupites Street 1, Riga, Latvia. ${ }^{4}$ Clinical Immunology Centre, Pauls Stradins Clinical University Hospital, Pilsonu Street 13, Riga, Latvia. ${ }^{5}$ Department of Infectology and Dermatology, Riga Stradins University, Dzirciema Street 16, Riga, Latvia. ${ }^{6}$ Anesthesia and Critical Care Research Group, Department of Clinical Medicine, Faculty of Health Sciences, University of Tromsø, 9037 Tromsø, Norway.

\section{Received: 3 September 2014 Accepted: 26 August 2015}

\section{Published online: 04 September 2015}

\section{References}

1. Sniecinski RM, Chandler WL. Activation of the hemostatic system during cardiopulmonary bypass. Anesth Analg. 2011;113(6):1319-33. doi:10.1213/ANE.0b013e3182354b7e.

2. Ranucci M, Baryshnikova E, Castelvecchio S, Pelissero G. Major bleeding, transfusions, and anemia: the deadly triad of cardiac surgery. Ann Thorac Surg. 2013. doi:10.1016/j.athoracsur.2013.03.015.

3. Kristensen KL, Rauer LJ, Mortensen PE, Kjeldsen BJ. Reoperation for bleeding in cardiac surgery. Interact Cardiovasc Thorac Surg. 2012;14(6):709-13. doi:10.1093/icvts/ivs050.

4. Welsby IJ, Podgoreanu MV, Phillips-Bute B, Morris R, Mathew JP, Smith PK, et al. Association of the 98T ELAM-1 polymorphism with increased bleeding after cardiac surgery. J Cardiothorac Vasc Anesth. 2010;24(3):427-33. doi:10.1053/j.jvca.2009.10.030

5. Sirgo G, Morales P, Rello J. PAl-1 gene: pharmacogenetic association of 4G/4G genotype with bleeding after cardiac surgery-pilot study. Eur J Anaesthesiol. 2009;26(5):404-11. doi:10.1097/EJA.0b013e3283240412.

6. Yavari M, Becker RC. Coagulation and fibrinolytic protein kinetics in cardiopulmonary bypass. J Thromb Thrombolysis. 2009;27(1):95-104. doi:10.1007/s11239-007-0187-5.

7. Chandler WL, Velan T. Estimating the rate of thrombin and fibrin generation in vivo during cardiopulmonary bypass. Blood. 2003;101(11):4355-62. doi:10.1182/blood-2002-08-2400.

8. Chandler WL, Velan T. Plasmin generation and D-dimer formation during cardiopulmonary bypass. Blood Coagul Fibrinolysis. 2004;15(7):583-91.

9. Ozolina A, Strike E, Jaunalksne I, Krumina A, Bjertnaes LJ, Vanags I. PAI-1 and t-PA/PAl-1 complex potential markers of fibrinolytic bleeding after cardiac surgery employing cardiopulmonary bypass. BMC Anesthesiol. 2012;12:27. doi:10.1186/1471-2253-12-27.

10. Jimenez Rivera JJ, Iribarren JL, Raya JM, Nassar I, Lorente L, Perez R, et al. Factors associated with excessive bleeding in cardiopulmonary bypass patients: a nested case-control study. J Cardiothorac Surg. 2007;2:17. doi:10.1186/1749-8090-2-17.

11. Iribarren JL, Jimenez JJ, Hernandez D, Brouard M, Riverol D, Lorente L, et al. Postoperative bleeding in cardiac surgery: the role of tranexamic acid in patients homozygous for the $5 \mathrm{G}$ polymorphism of the plasminogen activator inhibitor-1 gene. Anesthesiology. 2008;108(4):596-602. doi:10.1097/ALN.0b013e318167aecc.

12. Duggan E, O'Dwyer MJ, Caraher E, Diviney D, McGovern E, Kelleher D, et al. Coagulopathy after cardiac surgery may be influenced by a functional plasminogen activator inhibitor polymorphism. Anesth Analg. 2007;104(6):1343-7. doi:10.1213/01.ane.0000261267.28891.00. table of contents.

13. Burzotta F, lacoviello L, Di Castelnuovo A, Zamparelli R, D'Orazio A, Amore C, et al. 4G/5G PAl-1 promoter polymorphism and acute-phase levels of PAI-1 following coronary bypass surgery: a prospective study. J Thromb Thrombolysis. 2003;16(3):149-54. doi:10.1023/B:THRO.0000024052.79415.62.

14. Ozolina A, Strike E, Jaunalksne I, Serova J, Romanova T, Zake LN, et al. Influence of PAl-1 gene promoter-675 (4G/5G) polymorphism on fibrinolytic activity after cardiac surgery employing cardiopulmonary bypass. Medicina (Kaunas, Lithuania). 2012;48(10):515-20.

15. Kohler HP, Grant PJ. Plasminogen-activator inhibitor type 1 and coronary artery disease. N Engl J Med. 2000;342(24):1792-801. doi:10.1056/NEJM200006153422406.

16. Usalan C, Buyukhatipoglu H. A dynamic comparative study concerning the effects of angiotensin-converting enzyme inhibitors and aldosterone receptor blockers on the fibrinolytic system. Clin Appl Thromb Hemost. 2008;14(2):203-9. doi:10.1177/1076029607303614.
17. Felmeden DC, Lip GY. The renin-angiotensin-aldosterone system and fibrinolysis. J Renin-Angiotensin-Aldosterone Syst. 2000;1(3):240-4. doi:10.3317/jraas.2000.036.

18. Alhenc-Gelas F, Richard J, Courbon D, Warnet JM, Corvol P. Distribution of plasma angiotensin I-converting enzyme levels in healthy men: relationship to environmental and hormonal parameters. J Lab Clin Med. 1991;117(1):33-9.

19. Chandler WL, Fitch JC, Wall MH, Verrier ED, Cochran RP, Soltow LO, et al. Individual variations in the fibrinolytic response during and after cardiopulmonary bypass. Thromb Haemost. 1995;74(5):1293-7.

20. Jankun J, Skrzypczak-Jankun E. Plasminogen activator inhibitor with very long half-life (VLHL PAl-1) can reduce bleeding in PAl-1-deficient patients. Cardiovasc Hematol Disord Drug Targets. 2013;13(2):144-50.

21. Haselbauer A, Haberbosch W, Tillmanns H, Gardemann A. The impact of the PAl-1 A((-844))G promoter polymorphism on the risk and extent of coronary heart disease. Thromb Haemost. 2002;88(4):697-8. doi:10.1267/th02100697.

22. Abboud N, Ghazouani L, Saidi S, Ben-Hadj-Khalifa S, Addad F, Almawi WY, et al. Association of PAl-1 4G/5G and -844G/A gene polymorphisms and changes in PAl-1/tissue plasminogen activator levels in myocardial infarction: a case-control study. Genet Test Mol Biomarkers. 2010;14(1):23-7. doi:10.1089/gtmb.2009.0039.

23. Morange PE, Henry M, Tregouet D, Granel B, Aillaud MF, Alessi MC, et al. The A -844G polymorphism in the PAl-1 gene is associated with a higher risk of venous thrombosis in factor $\mathrm{V}$ Leiden carriers. Arterioscler Thromb Vasc Biol. 2000;20(5):1387-91.

24. Moore JH, Smolkin ME, Lamb JM, Brown NJ, Vaughan DE. The relationship between plasma t-PA and PAl-1 levels is dependent on epistatic effects of the ACE I/D and PAI-1 4G/5G polymorphisms. Clin Genet. 2002;62(1):53-9.

25. Pola E, Gaetani E, Pola R, Papaleo P, Flex A, Aloi F, et al. Angiotensinconverting enzyme gene polymorphism may influence blood loss in a geriatric population undergoing total hip arthroplasty. J Am Geriatr Soc. 2002;50(12):2025-8.

26. Della-Morte D, Guadagni F, Palmirotta R, Ferroni P, Rundek T. D allele of ACE gene insertion/deletion polymorphism: a marker for risk of ischemic stroke. Pharmacogenomics. 2013;14(1):16.

27. Zhou L, Xi B, Wei Y, Shen W, Li Y. Meta-analysis of the association between the insertion/deletion polymorphism in ACE gene and coronary heart disease among the Chinese population. J Renin Angiotensin Aldosterone Syst. 2012;13(2):296-304. doi:10.1177/1470320311434242.

28. Jackson A, Brown K, Langdown J, Luddington R, Baglin T. Effect of the angiotensin-converting enzyme gene deletion polymorphism on the risk of venous thromboembolism. Br J Haematol. 2000;111(2):562-4.

29. Welsby IJ, Podgoreanu MV, Phillips-Bute B, Mathew JP, Smith PK, Newman MF, et al. Genetic factors contribute to bleeding after cardiac surgery. J Thromb Haemost. 2005;3(6):1206-12. doi:10.1111/j.1538-7836.2005.01337.x.

30. Iribarren Sarrias I, Jimenez Rivera J, Nassar I, Salido E, Garrido P, Lorente L, et al. Predictive genetic factors for bleeding in cardiac surgery patients with cardiopulmonary bypass. Crit Care. 2006;10 Suppl 1:225.

31. Tomita H, Ina $Y$, Sugiura $Y$, Sato $S$, Kawaguchi $H$, Morishita M, et al. Polymorphism in the angiotensin-converting enzyme (ACE) gene and sarcoidosis. Am J Respir Crit Care Med. 1997;156(1):255-9.

32. Verschuur M, Jellema A, Bladbjerg EM, M Feskens EJ, Mensink RP, Moller L, et al. The plasminogen activator inhibitor-1 (PAl-1) promoter haplotype is related to PAI-1 plasma concentrations in lean individuals. Atherosclerosis. 2005;181(2):275-84. doi:10.1016/j.atherosclerosis.2005.01.036.

33. D'Angelo A, Kluft C, Verheijen JH, Rijken DC, Mozzi E, Mannucci PM. Fibrinolytic shut-down after surgery: impairment of the balance between tissue-type plasminogen activator and its specific inhibitor. Eur J Clin Invest. 1985;15(6):308-12.

34. Matsubara Y, Hayakawa T, Tsuda T, Takeshita E, Watanabe G, Murata M, et al. Angiotensin converting enzyme insertion/deletion polymorphism is associated with plasma antigen levels of plasminogen activator inhibitor-1 in healthy Japanese population. Blood Coagul Fibrinolysis. 2000;11(2):115-20.

35. DeLoughery TG. Coagulation defects in trauma patients: etiology, recognition, and therapy. Crit Care Clin. 2004;20(1):13-24.

36. Gaudino M, Zamparelli R, Andreotti F, Burzotta F, lacoviello L, Glieca F, et al. Normothermia does not improve postoperative hemostasis nor does it reduce inflammatory activation in patients undergoing 
primary isolated coronary artery bypass. I Thorac Cardiovasc Surg. 2002;123(6):1092-100

37. Ternstrom L, Radulovic V, Karlsson M, Baghaei F, Hyllner M, Bylock A, et al. Plasma activity of individual coagulation factors, hemodilution and blood loss after cardiac surgery: a prospective observational study. Thromb Res. 2010;126(2):e128-33. doi:10.1016/j.thromres.2010.05.028.

38. Chapman MP, Moore EE, Ramos CR, Ghasabyan A, Harr JN, Chin TL, et al. Fibrinolysis greater than $3 \%$ is the critical value for initiation of antifibrinolytic therapy. J Trauma Acute Care Surg. 2013;75(6):961-7. doi:10.1097/TA.0b013e3182aa9c9f. discussion 7.

39. Ramos CR, Moore EE, Manco-Johnson ML, Silliman CC, Chapman MC, Banerjee A. The incidence and magnitude of fibrinolytic activation in trauma patients: a rebuttal. J Thromb Haemost. 2013;11(7):1435-7. doi:10.1111/jth.12240.

40. Eriksson P, Kallin B, van't Hooft FM, Bavenholm P, Hamsten A. Allele-specific increase in basal transcription of the plasminogen-activator inhibitor 1 gene is associated with myocardial infarction. Proc Natl Acad Sci U S A. 1995;92(6):1851-5.

\section{Submit your next manuscript to BioMed Central and take full advantage of:}

- Convenient online submission

- Thorough peer review

- No space constraints or color figure charges

- Immediate publication on acceptance

- Inclusion in PubMed, CAS, Scopus and Google Scholar

- Research which is freely available for redistribution 